\title{
Self-Regulation of Slow Cortical Potentials in Psychiatric Patients: Depression ${ }^{1}$
}

\author{
Frank Schneider ${ }^{2}$ \\ University of Tübingen, Germany, and University of Pennsylvania, Philadelphia, U.S.A.
}

Hans Heimann, Regina Mattes, and Werner Lutzenberger

University of Tübingen, Germany

Niels Birbaumer

University of Tübingen, Germany, and Università Degli Studi, Padova, Italia

Findings on depressive patients indicate that depressives have electrophysiological characteristics similar to those of schizophrenics, in that they exhibit reduced Contingent Negative Variation (CNV) amplitudes and more distinct Postimperative Negative Variations (PINVs) than normal controls. In a biofeedback experiment, 8 medicated male inpatients with the DSM III-R diagnosis of "Bipolar Disorder, Depressive," and "Major Depression" demonstrated no impairment in the self-regulation of Slow Cortical Potentials (SCP) in comparison to schizophrenics in terms of increasing and suppressing negativity. Continuous visual SCP feedback is presented to the patient as a horizontally moving rocket in a video game format. The direction changes of the rocket represented SCP changes at each point in time, recorded by the central EEG (based on the pretrial baseline). Depressives demonstrated SCP self-regulation across 20 sessions, although with many between-and-within variations. The 8 male controls were unable to regulate their SCPs across 5 sessions. This result contradicts other findings of our laboratory on normal controls. Motivational

\footnotetext{
${ }^{1}$ The authors are grateful to Waldemar Himer, Thomas Elbert, and Brigitte Rockstroh for their theoretical and technical support. Furthermore, we would like to thank Monika Wende and Gudrun Renz for their help during the experimental sessions and their assistance in evaluating the data. We would also like to thank Ilse M. Zalaman for her assistance in the preparation of this manuscript. Research was supported by the Bundesminister für Forschung und Technologie, Germany and the Deutsche Forschungsgemeinschaft.

${ }^{2}$ Address all correspondence to Dr. Frank Schneider, Department of Psychiatry, University of Pennsylvania, 10th Floor, Gates Building, Philadelphia, Pennsylvania 19104.
} 
factors and insufficient operant reinforcement (financial reward) may have facilitated this effect.

Descriptor Key Words: slow cortical potentials; depression; biofeedback; instrumental learning; CNV.

Slow-varying shifts of the surface-recorded EEG - so-called Slow Cortical Potentials (SCPs) - are considered to represent neuronal processes involved in regulating excitability in underlying cortical networks (Elbert, in press; McCallum, 1988; Rockstroh, Elbert, Canavan, Lutzenberger, \& Birbaumer, 1989) and indicate preparatory resources for subsequent cerebral performance. We assume that excitability is regulated by information processing and preparatory demands. Knowledge gains from basic research have also been used to investigate information-processing disorders and to study the behavior of psychiatric patients (Timsit-Berthier et al., 1986, 1987).

Under normal circumstances, after termination of the imperative stimulus in a two-stimulus-paradigm, in healthy subjects the EEG-DC-level returns to baseline within $300-500 \mathrm{msec}$. Findings of such electrophysiological investigations were nosologically nonspecific: Observations of depressives in comparison to schizophrenic patients suggested a trend toward smaller Contingent Negative Variation (CNV) and a tendency to produce prolonged Postimperative Negative Variations (PINV) (Abraham \& McCallum, 1976; Bolz \& Giedke, 1980; Claverie, Brun, Nizard, Brenot, \& Paty, 1984; Elton, DeJong, \& Ferstl, 1980; Rizzo et al., 1979; Roth, Duncan, Pfefferbaum, \& Timsit-Berthier, 1986; Sartory, 1986; Small \& Small, 1971; Timsit-Berthier, Delaunoy, Koninckx, \& Rousseau, 1973; Timsit-Berthier et al., 1986). In normals this PINV occurs only in experimental situations of unexpected contingencies or loss of control over aversive events or unpredictably gained control (Kathmann, Jonitz, \& Engel, 1990). However, Timsit-Berthier et al. (1987) and Pierson, Ragot, Ripoche, and Lesevre (1987) showed an increase in CNV-amplitude in anhedonic subjects and depressives with anxiety symptomatology.

In another article we reported that schizophrenics, after extensive training, could systematically modify their SCPs when exposed to biofeedback and instrumental conditioning (Schneider, Rockstroh, Heimann, Lutzenberger, Mattes, Elbert, Birbaumer, \& Bartels, 1992). Our supposition is that schizophrenics, as well as individuals with high anhedonia scores (Elbert, Lutzenberger, Rockstroh, \& Birbaumer, 1983) may suffer from impaired regulation of cortical excitability, since they were able to produce negativity, but unable to modify their SCPs during the first few training sessions. Previous studies, however, demonstrated that most of the controls were able to modify their SCPs after 2 sessions (summarized in Rockstroh et al., 1989). 
Table I. Description (Demographic Data) of the Depressive Patients

\begin{tabular}{|c|c|c|c|c|c|}
\hline Patient & $\begin{array}{c}\text { Diagnosis } \\
\text { (DSM-III-R) }\end{array}$ & Age & $\begin{array}{l}\text { Duration of } \\
\text { illness } \\
\text { (years) }\end{array}$ & $\begin{array}{c}\text { Number of } \\
\text { hospitalizations }\end{array}$ & Medication \\
\hline 1 & 296.53 & 38 & 11 & 5 & Doxepin \\
\hline 2 & 296.53 & 56 & 15 & 2 & $\begin{array}{l}\text { Amitryptline } \\
\text { Lorazepam }\end{array}$ \\
\hline 3 & 296.33 & 47 & 2 & 3 & $\begin{array}{l}\text { Doxepin } \\
\text { Lithium } \\
\text { Lorazepam }\end{array}$ \\
\hline 4 & 296.22 & 50 & 3 & 2 & $\begin{array}{l}\text { Amitryptline } \\
\text { Perazine }\end{array}$ \\
\hline 5 & 296.33 & 50 & 3 & 1 & $\begin{array}{l}\text { Doxepin } \\
\text { Perazine }\end{array}$ \\
\hline 6 & 296.33 & 45 & 1 & 2 & $\begin{array}{l}\text { Doxepin } \\
\text { Levomepromazine }\end{array}$ \\
\hline 7 & 296.33 & 47 & 1 & 2 & $\begin{array}{l}\text { Doxepin } \\
\text { Lithium }\end{array}$ \\
\hline 8 & 296.33 & 49 & 6 & 1 & $\begin{array}{l}\text { Doxepin } \\
\text { Perazine }\end{array}$ \\
\hline Mean & & 47.8 & 5.3 & 2.3 & \\
\hline
\end{tabular}

The objective of this study was to investigate whether depressives exhibit the same cognitive deficits as schizophrenics in terms of impaired SCP control.

\section{METHOD}

The experimental procedure employed in this study was identical to the one reported in Schneider et al. (1992) and Schneider et al. (in press).

\section{Subjects}

Participating subjects were 8 right-handed (Edinburgh Inventory, Oldfield, 1971) medicated depressive male inpatients and 8 normal male controls (Table I). On the average, patients were hospitalized twice and their mean duration of illness was 5 years. Psychopathological assessment at the beginning of the study showed high impairment in psychosocial adjustment (Global Assessment Scale, Endicott, Spitzer, Fleiss, \& Cohen, 1976: $M=40.1 ; S D=7.95$ ), many depressive symptoms on the rating scale (Hamilton Depression Scale, Hamilton, 1960: $M=21.3$; $S D=4.74$ ) 
and an acute psychiatric illness (Brief Psychiatric Rating Scale, Overall, \& Gorham, 1962: $M=46.5 ; S D=6.72$ ). Diagnoses "Major Depression" or "Bipolar Disorder, Depressive" were established with the Structured Clinical Interview in accordance with DSM III-R, SCID (German version: Wittchen, Zaudig, Schramm, Spengler, Mombour, Klug, \& Horn, 1987). State of illness was either subacute or chronic at the beginning of the biofeedback training. All patients were on tricyclic antidepressive medication (mean of $150 \mathrm{mg}$ ), with 4 receiving additional low doses of derivatives of phenothiazine; 2 received lorazepam and 2 lithium.

The mean age of the right-handed (Edinburgh Inventory, Oldfield, 1971 ) male controls was 38.5 years $(S D=9.60$; range $30-55$ years). None of the controls had a history of previous psychiatric disorders or neurological illnesses and they were asked not to ingest medications known to influence psychophysiological performance 3 months before the study was set to begin.

\section{Apparatus and Physiological Recording}

Computers (DEC LSI $11 / 2$ and Atari 1040 ST) were used for stimuli generation and data storage (sampling frequency $100 \mathrm{~Hz}$ ). The EEG was recorded from $C_{z}$ (according to the international 10-20-system; time constant: $30 \mathrm{~s}$, high-frequency cutoff: $30 \mathrm{~Hz}$ ). In Vivo Metrics silver disk electrodes, chlorinated before each use, were affixed with Grass EC2 paste, which acted as a conducting agent. The midpoint of a fixed $10 \mathrm{k} \Omega$ shunt attached to the subjects' earlobes was used as reference point. Electrode sites on the subjects' scalp were cleaned with alcohol and the upper layers of the skin abraded with a sterile lancet in order to reduce impedance to below $5 \mathrm{k} \Omega$. Vertical EOG recordings were taken via Beckman $\mathrm{Ag} / \mathrm{AgCl}$ macro-electrodes $1 \mathrm{~cm}$ above and $1 \mathrm{~cm}$ below the right eye.

\section{Design and Procedure}

Each 8-s trial provided continuous visual feedback of SCPs. The feedback stimulus - the outline of a rocket ship - appeared on a 30 $\times 40-\mathrm{cm}$ TV screen placed $2 \mathrm{~m}$ in front of the subject at eye level. The rocket moved in a horizontal plane through a gap. In each trial the subject was asked to move the rocket from left to right out of a starting gap toward a letter ("A" or "B"). Negative slow potential shifts, referring to baseline level, moved the rocket toward the right on trials, where "A" was presented; whereas suppression of negativity or a positive slow 
potential shift did so on trials, where "B" was presented. Assignment of trial type (negativity/positivity) to the discriminative stimuli (the letters "A" or "B") was varied randomly between subjects. Subjects were told that the distance the rocket moved to the right signaled the correct response. They received no information on how to move the rocket. However, they were informed correctly that the task was to change "their brain activity" into two opposite directions ("A" or " $B$ ").

Subjects received money at the end of each session. The amount of money received depended on their performance [between $\$ 2$ and $\$ 8$ (US) per session]. We calculated the actual SCP differentiation between all "negativity" and "positivity" trials in microvolts in each session and exchanged this value into bonus money.

The position of the rocket was a linear function of the integrated EEG and based on the mean of a 1-s pretrial baseline. To equate the difficulty of A-and-B feedback trials, a constant offset of $-6 \mu \mathrm{V}$ was included in the pretrial baseline in order to compensate for increased negativity elicited by the anticipated trial onset. Trials were started by the computer only when the pretrial baseline was free of artifacts caused by body or eye movements. A time-out contingency was used to prevent forward rocket excursions whenever vertical eye movements of the same polarity as the required slow potentials were detected (Elbert, Rockstroh, Lutzenberger, \& Birbaumer, 1980).

To assess response control when feedback was absent, "transfer" trials were included. These trials contained the letters " $A$ " or "B," but no feedback (the rocket was missing). Before the onset of transfer trials subjects were told that their task now consisted of moving an imaginary rocket as required by the appearance of an "A" or "B." Each session consisted of 110 trials comprising alternate blocks of 30 feedback trials and 20 transfer trials. Within each block, "A" and "B" trials were presented in pseudorandom order. The time lapse between the end of one trial and the next pretrial baseline varied randomly between 4 and 12 s. Depressives participated in 20 consecutive sessions, healthy controls in 5 sessions.

\section{Data Reduction and Analysis}

Trials where the DC-shift of the EEG channel exceeded $100 \mu \mathrm{V}$ or $70 \mu \mathrm{V}$ in the EOG channel were excluded. Vertical eye movement changes were assessed in the same manner as SCPs: There were no significant differences between groups in the different conditions. SCP calculations were done by subtracting the mean SCP registered during the last second 
Table II. Mean Differentiation ( + SE) between Negativity and Negativity Suppression Trials in Microvolts

\begin{tabular}{lccccc}
\hline & Controls & \multicolumn{4}{c}{ Patients } \\
\cline { 2 - 5 } & Sessions & Sessions & Sessions & Sessions & Sessions \\
& $1-5$ & $1-5$ & $6-10$ & $11-15$ & $16-20$ \\
\hline Transfer 1 & 0.78 & -0.75 & 7.31 & 4.33 & 4.13 \\
& \pm 1.96 & \pm 1.95 & \pm 4.61 & \pm 2.46 & \pm 3.97 \\
Feedback 1 & -1.09 & 2.63 & 6.44 & 2.32 & 4.41 \\
& \pm 0.88 & \pm 0.96 & \pm 4.84 & \pm 3.18 & \pm 4.27 \\
Feedback 2 & 0.43 & 3.89 & 5.83 & 4.50 & 1.19 \\
& \pm 1.23 & \pm 1.07 & \pm 4.80 & \pm 4.62 & \pm 4.70 \\
Transfer 2 & 0.88 & 3.42 & 5.84 & 6.35 & 4.54 \\
& \pm 1.44 & \pm 0.80 & \pm 4.88 & \pm 4.24 & \pm 3.08 \\
\hline
\end{tabular}

of the pretrial period from the mean SCP recorded during the $8 \mathrm{~s}$ of the feedback period. Only the data from the last feedback-and-transfer blocks were analyzed, since the first blocks were used as practice sessions.

\section{RESULTS}

\section{SCP Differentiation}

Healthy controls showed no significant SCP self-regulation within the first 5 training sessions (see Table II). Data comparison of the first 5 training sessions for depressive patients and controls revealed an impaired performance of normals under all transfer conditions (see Table II for mean values). This was documented by a 4-way ANOVA [Group, Trial Block (feedback, transfer), Session (1-5), and Differentiation (negativity, negativity suppression) ( 3 repeated measures factors)], where the main effect Group $[F(1,14)=17.71 ; p<.001]$ and the interaction Group $\times$ Differentiation reached significance $[F(1,14)=4.72 ; p=.048]$. The main effect Differentiation $[F(1,14)=9.74 ; p=.008]$ was the result of this interaction.

Paired $t$-tests demonstrated that this differentiation in controls was significant neither for the second transfer block $[0.88 \mu \mathrm{V}: t(7)=0.61]$ nor for the second feedback block $[0.43 \mu \mathrm{V}: t(7)=0.35]$.

In comparison to healthy controls depressive patients could differentiate significantly across the first 5 sessions in the second feedback [3.89 


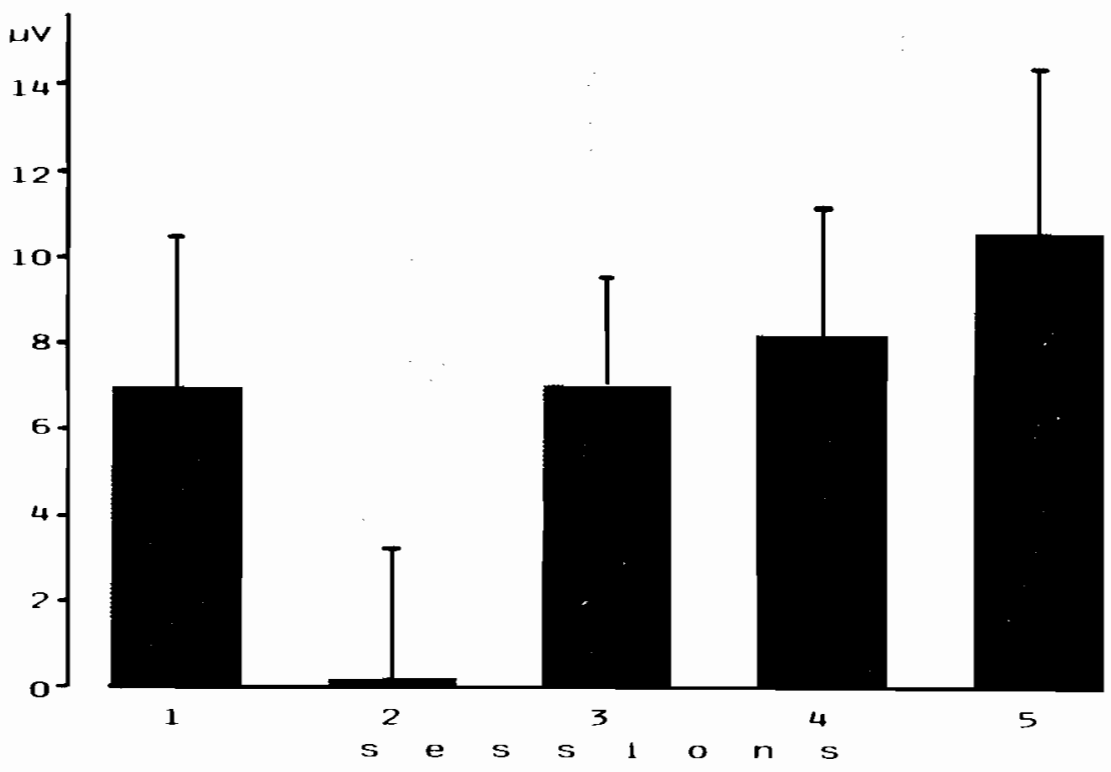

Fig. 1. Mean differentiation of SCPs in microvolts in the second transfer block between negativity and negativity suppression trials in 8 depressive patients across 5 sessions (bars mark microvolt averages).

$\mu \mathrm{V}: t(7)=3.65 ; p=.004]$ and transfer block $[3.42 \mu \mathrm{V}: t(7)=2.26 ; p=$ .012 ; Figure 1].

The average SCP-differentiation in depressive patients increased from $3.42 \mu \mathrm{V}$ in the first 5 sessions to $4.54 \mu \mathrm{V}[\iota(7)=1.24 ; p=.092]$ in sessions 15-20 (see Table II and Figure 2). Although sessions 6-10, 11-15, and 16-20 demonstrated an increase in mean values, the differences were nonsignificant, owing to an increase in standard deviations.

During the second feedback block in sessions 1-5, depressives demonstrated significant SCP differentiation, but no significant differentiation in the following 15 sessions.

\section{Psychopathological Status and SCP Differentiation}

Correlations between psychopathology and SCP regulation performance revealed the influence of psychopathology on differentiation performance: Data show that the ability to regulate SCPs (mean difference between the required negativity increase and negativity suppression in 


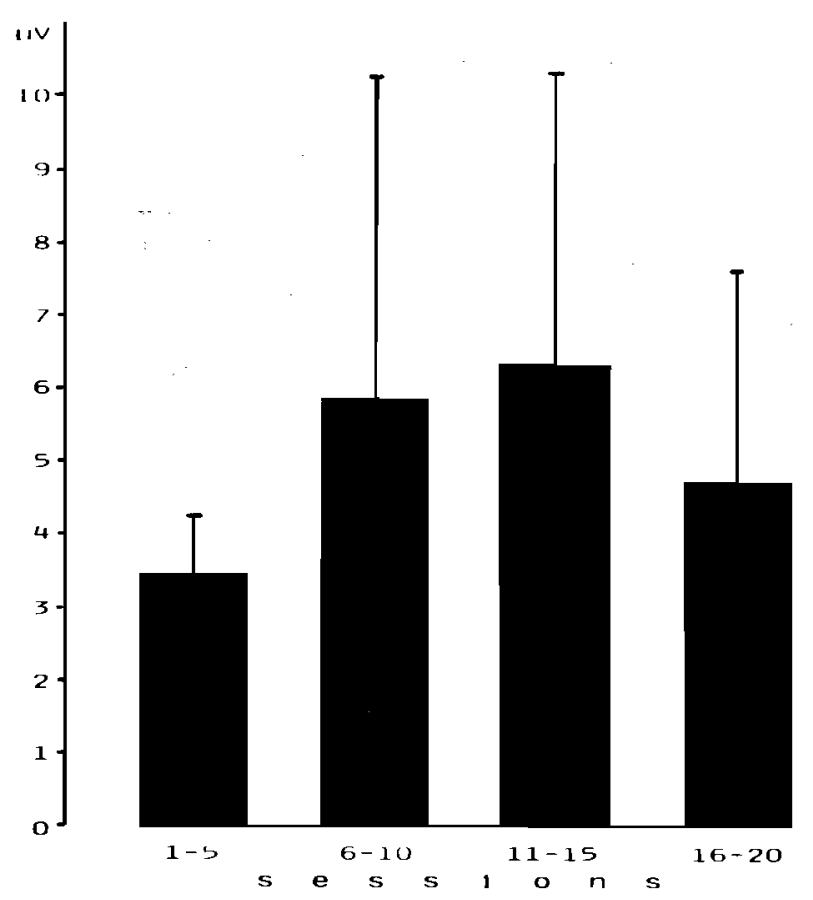

Fig. 2 Mean differentiation of SCPs in microvolts in the second transfer block between negativity and negativity suppression trials in 8 depressive patients across 20 sessions.

microvolts in the last 3 sessions) correlated minimally with (a) symptomatology at the beginning of the study (HAMD: $r=.56$; n.s.; BPRS: $r=.13$; n.s.; GAS: $r=-.52$, n.s.); (b) length of illness (duration of illness in months: $r=-.38$; n.s.) and onset of illness (age: $r=-.67$; $p<.05$ ), and (c) multiple hospitalizations $(r=.82 ; p<.01)$.

\section{DISCUSSION}

The findings show that depressive patients could differentiate SCPs significantly between required negativity and negativity suppression. Thus, SCP self-regulation impairment may be specific for schizophrenic patients, as no comparable deficits have been found for depressives. There might be a connection between self-regulation and the CNV findings in depres- 
sives (Timsit-Berthier et al., 1986) or anhedonic subjects (Pierson et al., 1987). Both groups in these CNV studies exhibited an increased CNV amplitude in comparison to healthy controls. These findings are unusual in that they differ from the typical CNV findings on depressives. However, Elbert et al. (1983) were able to demonstrate that healthy controls with higher anhedonia scores clearly exhibited reduced SCP-regulation ability in a slightly different SCP self-regulation task within 2 sessions. Their results were similar to our results obtained in the second session of our experiment (cf. Fig. 1). Anhedonia is considered to be a profound deficit in pleasure experience. Meehl (1962) considers anhedonia as one of four paramount source traits which characterize the schizotypic personality. The findings on normal controls with high anhedonia scores when compared with findings on depressives in this study may indicate that anhedonia is more closely related to schizophrenia than to depression. A similar problem may be present in other psychopathological groups such as hyperactive children, whose anhedonia scores are normally elevated. In this context Lubar and Lubar (1984) demonstrated prolonged training periods for SMR biofeedback acquisition.

In contrast to many reported findings on healthy controls (summarized by Rockstroh et al., 1989) the controls in this study were unable to differentiate SCPs in the feedback-and-transfer trials. This is quite unusual as another group of 12 controls under identical conditions in the same laboratory (Schneider et al., 1992) and a second group of 11 controls in another laboratory (using a tantamount design; Roberts, Birbaumer, Lutzenberger, Elbert, \& Rockstroh, 1989) demonstrated operant control after only a few sessions.

The three groups of control subjects differed only in age and vocation: The controls in this experiment were much older than the other subjects (mean age was 40 years). Nevertheless, age alone could not have caused this effect, since the participating depressive patients were even older than the controls and they were able to regulate their SCPs. In comparison to other studies whose subjects mostly comprised college students, this study used subjects employed in the academic field. They came to the laboratory in the evening after they had finished work. In retrospect we are of the opinion that the financial reward may have been too small and consequently its use as an operant reinforcer was ineffective.

If one compares the depressives in our study with the 12 controls in our study with schizophrenic patients (Schneider et al., 1992) then depressives demonstrated impaired SCP regulation: On the average depressives attained $3.42 \mu \mathrm{V}$ in the second transfer, while controls attained $6.66 \mu \mathrm{V}$.

Since the maximum difference between negativity increase and suppression could only be obtained during transfer trials, the difference be- 
tween required negativity increase and negativity suppression during transfer was the most important indicator for learned SCP regulation. However, our controls did not even exhibit differentiation in the feedback trials, so we were forced to assume that the above-mentioned intervening variables may have been responsible for this learning effect.

The demonstrated SCP-differentiation performance of the 8 depressives varied considerably within and between subjects. Observed motivation of the patients decreased considerably during the middle of the training (i.e., patients exhibited increasing tiredness) and only increased again during the last sessions. Findings seem to indicate that depressives were unable to maintain consistent SCP differentiation across 20 sessions.

The psychopharmacological medication appeared to have no effect on the SCP self-regulation task: Each of the depressive patients was under tricyclic antidepressive medication with an average dose of $150 \mathrm{mg}$. In contrast to the healthy controls, the medicated patients were able to perform the SCP regulation task. Some of the depressives received additional low doses of derivatives of phenothiazine, benzodiazepines, or lithium. We have no reason to assume that these medications influence task performance. As the sample was small we did not analyze the data statistically.

Although performance averages increased significantly during the course of the experiment, one should not attach too much weight to this finding, since the sample was small and the results only approached significance. Two patients were responsible for the greatest variances in the second part of the training (Table II): One patient (patient 1) achieved up to $46 \mu \mathrm{V}$ in the last 10 sessions of the second transfer block, while another patient (patient 5) "unlearned" the SCP-regulation demonstrated during the first few sessions in the second transfer block. However, at the end of the training this patient achieved very high negative SCP differentiations (up to $-19 \mu \mathrm{V}$ ).

Depressives demonstrated increasing control of SCP regulation across the 20 sessions. Stronger differentiation in the transfer trials than in the feedback trials (see above) signaled control of SCP regulation.

\section{REFERENCES}

Abraham, P., \& McCallum, W. C. (1976). The CNV and its relation to specific psychiatric syndromes. In W. C. McCallum \& J. R. Knott (Eds.), The responsive brain (pp. 144-149). Bristol: Wright.

Bolz, J., \& Giedke, H. (1980). Controllability of an aversive stimulus in depressed patients and healthy controls: A study using slow brain potentials. Biological Psychiatry, 15, 441452. 
Clavarie, B., Brun, A., Nizard, A., Brenot, P. \& Paty, J. (1984). Multiparametric outlines with CNV: Application to depressive syndromes. In R. Karrer, J. Cohen, \& P. Tueting (Eds.), Brain and information. Annals of the New York Academy of Science, 425, 556-564.

Elbert, T. (in press). Slow cortical potentials reflect the regulation of cortical excitability. In W. C. McCallum (Ed.), Slow potential changes in the human brain. New York: Plenum.

Elbert, T., Rockstroh, B., Lutzenberger, W., \& Birbaumer, N. (1980). Biofeedback of slow cortical potentials. I. Electroencephalography and Clinical Neurophysiology, 48, 293-301.

Elbert, T., Lutzenberger, W., Rockstroh, B., \& Birbaumer, N. (1983). When regulation of slow brain potentials fails - A contribution to the psychophysiology of perceptual aberration and anhedonia. In C. Perris, D. Kemali, \& M. Koukkou-Lehmann (Eds.), Clinical neurophysiological aspects of psychopathological conditions (pp. 99-106). Basel: Karger.

Elton, M., DeJong, R., \& Ferstl, R. (1980). The CNV in reactive depressives and normals, Biological Psychology, 11, 28.

Endicott, J., Spitzer, R. L., Fleiss, J. L., \& Cohen, J. (1976). The Global Assessment Scale. A procedure for measuring overall severity of psychiatric disturbance. Archives of General Psychiatry, 33, 766-771.

Hamilton, M. (1960). A rating scale for depression. Joumal of Neurology, Neurosurgery and Psychiatry, 23, 56-62.

Kathmann, N., Jonitz, L., \& Engel, R. R. (1990). Cognitive determinants of the postimperative negative variation. Psychophysiology, 27, 256-263.

Lubar, J. F., \& Lubar, J. (1984). Electroencephalographic biofeedback of SMR and beta for the treatment of attention deficit disorders in a clinical setting. Biofeedback and SelfRegulation, 9, 1-23.

McCallum, W. C. (1988). Potentials related to expectancy, preparation and motor activity. In T. W. Picton (Ed.), Human event-related potentials - Handbook of electroencephalography and clinical neurophysiology, Vol. 3 (pp. 427-453). Amsterdam: Elsevier.

Meehl, P. (1962). Schizotoxia, schizotypy, schizophrenia. American Psychologist, 17, 827-838.

Oldfield, R. C. (1971). The assessment and analysis of handedness: The Edinburgh Inventory. Neuropsychologia, 9, 97-113.

Overall, D. E., \& Gorham, D. E. (1962). The Brief Psychiatric Rating Scale. Psychological Reports, 10, 799-812.

Pierson, A., Ragot, R., Ripoche, A., \& Lesevre, N. (1987). Electrophysiological changes elicited by auditory stimuli given a positive or negative value: A study comparing anhedonic with hedonic subjects. International Journal of Psychophysiology, 5, 107-123.

Rizzo, P. A., Amabile, G., Caporali, M., Pierelli, F., Spadoro, M., Zanasi, M., \& Morocutti, C. (1979). A longitudinal CNV study in a group of five bipolar cyclothymic patients. Biological Psychiatry, 14, 581-586.

Roberts, L., Birbaumer, N., Lutzenberger, W., Elbert, T., \& Rockstroh, B. (1989). Self-report during feedback regulation of slow cortical potentials. Psychophysiology, 26, 392-403.

Rockstroh, B., Elbert, T., Canavan, A., Lutzenberger, W., \& Birbaumer, N. (1989). Slow cortical potentials and behaviour (2nd ed.). Baltimore: Urban \& Schwarzenberg.

Roth, W. T., Duncan, C. C., Pfefferbaum, A., \& Timsit-Berthier, M. (1986). Applications of cognitive ERPs in psychiatric patients. In W. C. McCallum, R. Zappoli, \& F. Denoth (Eds.), Cerebral psychophysiology (pp. 419-438). Amsterdam: Elsevier.

Sartory, G. (1986). The contingent negative variation (CNV) in psychiatric states. In I. Martin \& D. Papakostopoulos (Eds.), Clinical and experimental neuropsychology (pp. 286-311). London: Croom Helm.

Schneider, F., Rockstroh, B., Heimann, H., Lutzenberger, W., Mattes, R., Elbert, T., Birbaumer, N., \& Bartels, M. (1992). Self-regulation of slow cortical potentials in psychiatric patients. Schizophrenia. Biofeedback and Self-Regulation, 17 (4).

Schneider, F., Elbert, T., Heimann, H., Welker, A., Stetter, F., Mattes, R., Birbaumer, N., \& Mann, K. (in press). Self-regulation of slow cortical potentials in psychiatric patients. Alcohol dependency. Biofeedback and Self-Regulation.

Small, J. G., \& Small, I. F. (1971). CNV correlations with psychiatric diagnosis. Archives of General Psychiatry, 25, 550-554. 
Timsit-Berthier, M., Delaunoy, J., Koninckx, N., \& Rousseau, J. (1973). Slow potential changes in psychology. I. Contingent negative variation. Electroencephalography and Clinical Neurophysiology, 35, 355-361.

Timsit-Berthier, M., Mantanus, H., Marissiaux, P., Ansseau, M., Doumont, A., Geenen, V., \& Legros, J. (1986). CNV and dopamine receptor reactivity: Correlations with the apomorphine test. In W. C. McCallum, R. Zappoli, \& F. Denoth (Eds.), Cerebral psychophysiology: Studies in event-related potentials (pp. 403-405). Amsterdam: Elsevier.

Timsit-Berthier, M., Mantanus, H., Ansseau, M., Devoitille, J.-M., Dal Mas, A., \& Legros, J.-J (1987). Contingent negative variation in major depressive patients. In R. Johnson Jr., J. W. Rohrbaugh \& R. Parasuraman (Eds.), Current trends in event-related potential research (pp. 762-771). Amsterdam: Elsevier.

Wittchen, H.-U. Zaudig, M., Schramm, E., Spengler, P., Mombour, W., Klug, J., \& Horn, R. (1987). Strukturiertes klinisches Interview für DSM-III-R (Testversion). Weinheim: Beltz. 